ORIGINAL ARTICLE

\title{
Epidemiology of injuries in English professional rugby union: part 2 training Injuries
}

\author{
J H M Brooks, C W Fuller, S P T Kemp, D B Reddin
}

Br J Sports Med 2005;39:767-775. doi: 10.1136/bjsm.2005.018408

See end of article for authors' affiliations

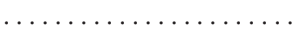

Correspondence to: Dr Fuller, University of Leicester, 154 Upper New Walk, Leics LE1 7QA, UK; cwf2@le.ac.uk

Accepted 22 March 2005
Objectives: To undertake a detailed epidemiological study of training injuries sustained by professional rugby union players in order to define their incidence, nature, severity, and causes.

Methods: A two season prospective design was used to study training injuries associated with 502 rugby union players at 11 English Premiership clubs. Team clinicians reported all training injuries on a weekly basis and provided details of the location, diagnosis, severity, and mechanism of each injury. Training exposures for individual players were recorded on a weekly basis. Loss of time from training and match play was used as the definition of an injury.

Results: The overall incidence of injury was 2.0 per 1000 player-hours, and each injury resulted on average in 24 days lost time. Recurrences, which accounted for 19\% of injuries, were more severe (35 days) than new injuries (21 days). Twenty two per cent of all training occurred during the preseason but $34 \%$ of all injuries were sustained in this period. Hamstring, calf, hip flexor/quadriceps, and adductor muscle injuries were the most common for backs, whereas hamstring, lateral ankle ligament, and lumbar disc/nerve root injuries predominated for forwards. Lumbar disc/nerve root, shoulder dislocation/ instability, and hamstring muscle injuries for forwards and hamstring muscle and anterior cruciate ligament injuries for backs caused the greatest number of days absence. Running was the predominant cause of injury for both forwards and backs, although the overall incidence and severity of injuries sustained during skills training were significantly greater than those sustained during conditioning training. Conclusions: On average, a club will have $5 \%$ of their players unavailable for selection as a consequence of training injuries.
$\mathrm{R}$ esults presented in part 1 of this epidemiological study confirmed the high incidence of injuries in professional club rugby union during competition. In addition, the study identified the most common and the most severe match injuries sustained by forwards and backs and assessed the incidence and severity of injuries as functions of risk factors such as playing position, time of match, season, and activity.

The incidence and nature of training injuries have not been separately reported for rugby union at professional club level, although some studies have grouped training injuries with match injuries and reported combined results for the nature of injuries. ${ }^{23}$ Combined values, however, depend strongly on the players' relative exposures to training and competition within the individual studies, and the incidence, severity, and nature of injuries cannot therefore be related to specific match and/or training risk factors. Brooks et al reported incidences of training injuries sustained by international players of 6.1/1000 player-hours, using an injury definition based on time lost from training and competition, and 2.6/ 1000 player-hours using a definition based on missed matches. These authors identified that most training injuries occurred to the lower (55\%) and upper $(20 \%)$ limbs and that the main diagnostic groups were muscle/tendon $(45 \%)$ and joint (non-bone)/ligament $(43 \%)$ injuries. Phillips et al reported an incidence of training injuries in professional club rugby league of 12.2/1000 player-hours, using a medical attention definition of injury, and 1.4/1000 player-hours using a semi-inclusive time loss definition. Gabbett ${ }^{6}$ reported that most training injuries in rugby league were to the lower limb and that the most common diagnosis was muscle strain.

Studies of international rugby union players showed that most training injuries $\left(64 \%,{ }^{4} 88 \%{ }^{3}\right)$ were sustained during rugby skills training, and Brooks et al ${ }^{4}$ highlighted that the incidence of injury from contact rugby skills training (20/ 1000 player contact training hours) was much higher than from non-contact rugby skills training (4.2/1000 player noncontact training hours). The incidence was also shown ${ }^{4}$ to depend on the type and exposure of conditioning activities undertaken within training programmes-for example, 2.1 injuries/1000 player-weight training-hours for weights, 24 injuries/1000 player-endurance training-hours for endurance running.

Seasonal variations in the incidence of training injuries have not been reported for rugby union. In semiprofessional rugby league, the early season incidence of training injuries was reported to be higher than during the remainder of the season, although this effect was not observed in professional rugby league. ${ }^{7}$ In professional soccer, higher numbers of injuries were reported during the preseason ${ }^{8}$ because of the high training volumes undertaken by players during this period but, when exposure was taken into account, the incidence was no higher in preseason than during the remainder of the season. ${ }^{9}$

Although earlier reports indicated that the incidence of injury during rugby union training may be much lower than during competition, the greater time spent training compared with competition means that the overall injury burden from training is still high. In addition, players are exposed to different risk factors during training because the demands placed on them are different from those experienced during match play. The aim of this study was to provide a detailed analysis of training injuries sustained in professional club rugby union that would complement the information reported for match injuries in part 1 of this study. ${ }^{1}$ Specific objectives of the study were to define the incidence, nature, severity, and causes of training injuries. 
Table 1 Anthropometric data for the sample population

\begin{tabular}{llll}
\hline Playing position & Age (years) & Stature $(\mathrm{cm})$ & Body mass $(\mathrm{kg})$ \\
\hline Forwards & $25.9(4.3)$ & $188.2(7.5)$ & $108.4(8.2)$ \\
Backs & $(\mathrm{n}=269)$ & $(\mathrm{n}=269)$ & $(\mathrm{n}=261)$ \\
& $24.8(3.9)$ & $181.3(5.5)$ & $89.4(6.7)$ \\
All players & $(\mathrm{n}=223)$ & $(\mathrm{n}=219)$ & $(\mathrm{n}=211)$ \\
\hline \multicolumn{2}{l}{ Values are mean (SD). } \\
\end{tabular}

\section{METHOD}

Players from 11 of the 13 rugby union clubs involved in the English Premiership during the 2002/03 and 2003/04 seasons (98 weeks) took part in the study. The sample population comprised players who were registered with the Rugby Football Union (RFU) and were first team squad members. Players were included or excluded from the study when they became or ceased to be members of a Premiership club's first team squad; this could occur as a result of a transfer, retirement, and a club's promotion to or relegation from the Premiership at the end of the first season. Over the period of the study, 502 players took part (277 forwards; 225 backs), of whom 279 were involved in both seasons. Except for six players, all eligible players agreed to take part and gave their written consent to be included in the study in accordance with RFU ethical guidelines. RFU registration numbers were used to identify players throughout the study in order to maintain players' anonymity and confidentiality of medical information.

A fully inclusive loss of time approach was adopted in the study for the primary definition of an injury: "any injury that prevents a player from taking a full part in all training activities typically planned for that day and match play for more than 24 hours from midnight at the end of the day the injury was sustained". So that results from this study could be compared with previous studies, injuries were also classified using a semi-inclusive loss of time definition: "all injuries resulting in a player missing at least one competitive match". However, unless specifically stated otherwise, an injury refers to the primary definition throughout the results and discussion. Injury severity was defined by the time it took a player to return to full fitness; full fitness was defined as "able to take a full part in training activities (typically planned for that day) and available for match selection." An injury was reported as a recurrence based on the judgment of the clinician reporting the injury. Absences because of illness and medical conditions were not included in the study.

Medical personnel at each club reported the details of every injury using a modified Orchard Sports Injury Classification System $^{10}$ and also provided a range of associated details related to the occurrence of the injury using a standard injury report form. Team fitness coaches recorded players' training schedules and exposure times on a weekly basis using a standard training report form. These data included the number of training sessions and the type and volume of training activities undertaken by forwards and backs. A one month pilot study of the injury report form, training report

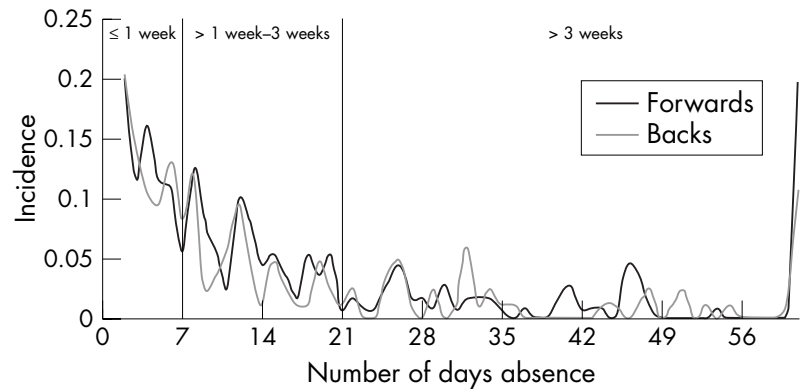

Figure 1 Injury incidence (number per 1000 player-hours) as a function of severity (days absence) for forwards and backs.

form, and injury recording process was undertaken at three of the Premiership clubs before the audit.

The age, stature, and preseason body mass of players were provided by clubs. Variations in body mass measurements between clubs were assessed using a reference player (forward), who was measured at each club (mean (SD) $103.5(0.7) \mathrm{kg}$; range $2.4 \mathrm{~kg}$ ).

\section{Data analysis}

Incidence of injury was recorded as the number of injuries/ 1000 player-hours of exposure. Significant differences in values for incidence and severity were assumed if the 95\% confidence intervals (CI) for the variables did not overlap. Anthropometric data were reported as the mean (SD). Differences in age, stature, and body mass between groups were identified with $t$ tests; significance was accepted at the $\mathrm{p} \leqslant 0.05$ level.

\section{RESULTS}

Table 1 shows the mean age, stature, and body mass of the cohort of players as functions of playing position. Significant differences $(p<0.001)$ were observed between forwards and backs for all three measures.

In total, 196409 hours of training (forwards, 112 280; backs, 84 130) and 395 injuries (forwards, 240; backs, 155) were recorded during the study. This equated to a mean of 21 (95\% CI 19 to 23 ) training injuries per team per season (forwards, 13 (95\% CI 11 to 15); backs, 8, (95\% CI 7 to 9)). In total, 9316 days of playing and training time were lost because of training injuries (forwards, 5809; backs, 3507). The mean number of training injuries per player was 0.6 (95\% CI 0.5 to 0.7 ) per season, and the mean amount of playing and/or training time lost per player was 12 days $(95 \%$ CI 11 to 13). Forwards received 0.6 injuries (95\% CI 0.5 to 0.7 ) per season and missed 13 days (95\% CI 11 to 15 ); backs received 0.5 injuries (95\% CI 0.4 to 0.6 ) per season and missed 10 days ( $95 \%$ CI 8 to 12 ).

\section{Incidence and severity of injury}

The mean (SD) incidence of injury per club was $2.0(0.69)$ per 1000 player-hours. Table 2 shows the incidence and severity of injuries as functions of playing position. There were no

Table 2 Incidence (number of injuries per 1000 player-hours) and severity (days absence) of new and recurrent injuries

\begin{tabular}{|c|c|c|c|c|c|c|}
\hline & \multicolumn{2}{|l|}{ Forwards } & \multicolumn{2}{|l|}{ Backs } & \multicolumn{2}{|l|}{ All } \\
\hline & Incidence $(95 \% \mathrm{Cl})$ & Severity $(95 \% \mathrm{Cl})$ & Incidence $(95 \% \mathrm{Cl})$ & Severity $(95 \% \mathrm{Cl})$ & Incidence $(95 \% \mathrm{Cl})$ & Severity $(95 \% \mathrm{Cl})$ \\
\hline New & $1.7(1.4$ to 1.9$)$ & 21 (17 to 25 ) & $1.6(1.3$ to 1.8$)$ & 21 (15 to 28 ) & $1.6(1.5$ to 1.8$)$ & 21 (17 to 25$)$ \\
\hline Recurrent & $0.45(0.33$ to 0.58$)$ & 37 (20 to 54$)$ & $0.27(0.16$ to 0.39$)$ & 30 (7 to 54$)$ & $0.38(0.29$ to 0.46$)$ & 35 (22 to 48$)$ \\
\hline All & $2.1(1.9$ to 2.4$)$ & 24 (19 to 29$)$ & $1.8(1.6$ to 2.1$)$ & 23 (16 to 29$)$ & $2.0(1.8$ to 2.2$)$ & $24(20$ to 27$)$ \\
\hline
\end{tabular}




\begin{tabular}{|c|c|c|c|c|c|c|}
\hline \multirow[b]{2}{*}{ Injury } & \multirow[b]{2}{*}{ Playing position } & \multicolumn{5}{|c|}{ Number of injuries (severity, assessed as days absence) } \\
\hline & & Head and neck & Upper limb & Trunk & Lower limb & All \\
\hline \multirow[t]{2}{*}{ Fractures and bone stress } & Forwards & $2(9)$ & $4(31)$ & $1(16)$ & $6(61)$ & $13(40)$ \\
\hline & Backs & $1(6)$ & $2(38)$ & $1(18)$ & $4(28)$ & $8(26)$ \\
\hline \multirow{2}{*}{ Joint (non-bone) and ligament } & Forwards & $3(6)$ & $15(51)$ & $33(22)$ & $56(24)$ & $107(27)$ \\
\hline & Backs & $0(-)$ & $11(59)$ & $8(17)$ & $24(38)$ & $43(39)$ \\
\hline \multirow{2}{*}{ Muscle and tendon } & Forwards & 1 (33) & $3(66)$ & $12(16)$ & $93(18)$ & $109(19)$ \\
\hline & Backs & $1(2)$ & $4(26)$ & $7(10)$ & $82(16)$ & $94(16)$ \\
\hline \multirow[t]{2}{*}{ Laceration and skin } & Forwards & $2(5)$ & $0(-)$ & $0(-)$ & 1 (13) & $3(7)$ \\
\hline & Backs & $1(4)$ & $0(-)$ & $0(-)$ & $0(-)$ & $1(4)$ \\
\hline \multirow[t]{2}{*}{ Central/peripheral nervous system } & Forwards & $3(27)$ & $0(-)$ & $2(142)$ & $1(3)$ & $6(61)$ \\
\hline & Backs & $4(12)$ & $0(-)$ & $0(-)$ & $2(34)$ & $6(19)$ \\
\hline \multirow[t]{2}{*}{ Other } & Forwards & $0(-)$ & $0(-)$ & $2(2)$ & $0(-)$ & $2(2)$ \\
\hline & Backs & $0(-)$ & $0(-)$ & $3(3)$ & $0(-)$ & $3(3)$ \\
\hline \multirow[t]{3}{*}{ All } & Forwards & $11(14)$ & $22(49)$ & $50(25)$ & $157(21)$ & $240(24)$ \\
\hline & Backs & $7(9)$ & $17(49)$ & 19 (12) & $112(21)$ & $155(23)$ \\
\hline & All & $18(12)$ & $39(49)$ & $69(21)$ & $269(21)$ & $395(24)$ \\
\hline
\end{tabular}

significant differences between forwards and backs for the incidence or severity of either new or recurrent injuries. The incidence of new injuries was significantly higher than that for recurrent injuries, but the severity of recurrent injuries was significantly greater than that for new injuries for both forwards and backs. Figure 1 shows incidence of injury as a function of severity. Minor injuries ( $\leqslant 7$ days absence) accounted for $37 \%$, moderate injuries ( $>1$ to 3 weeks) for $34 \%$, and major injuries ( $>3$ weeks) for $29 \%$ of all training injuries. The incidence of training injuries that resulted in a competitive match being missed (59\%) was 1.2 (95\% CI 1.0 to 1.3)/1000 player-hours (forwards, 1.3 (95\% CI 1.1 to 1.5 );

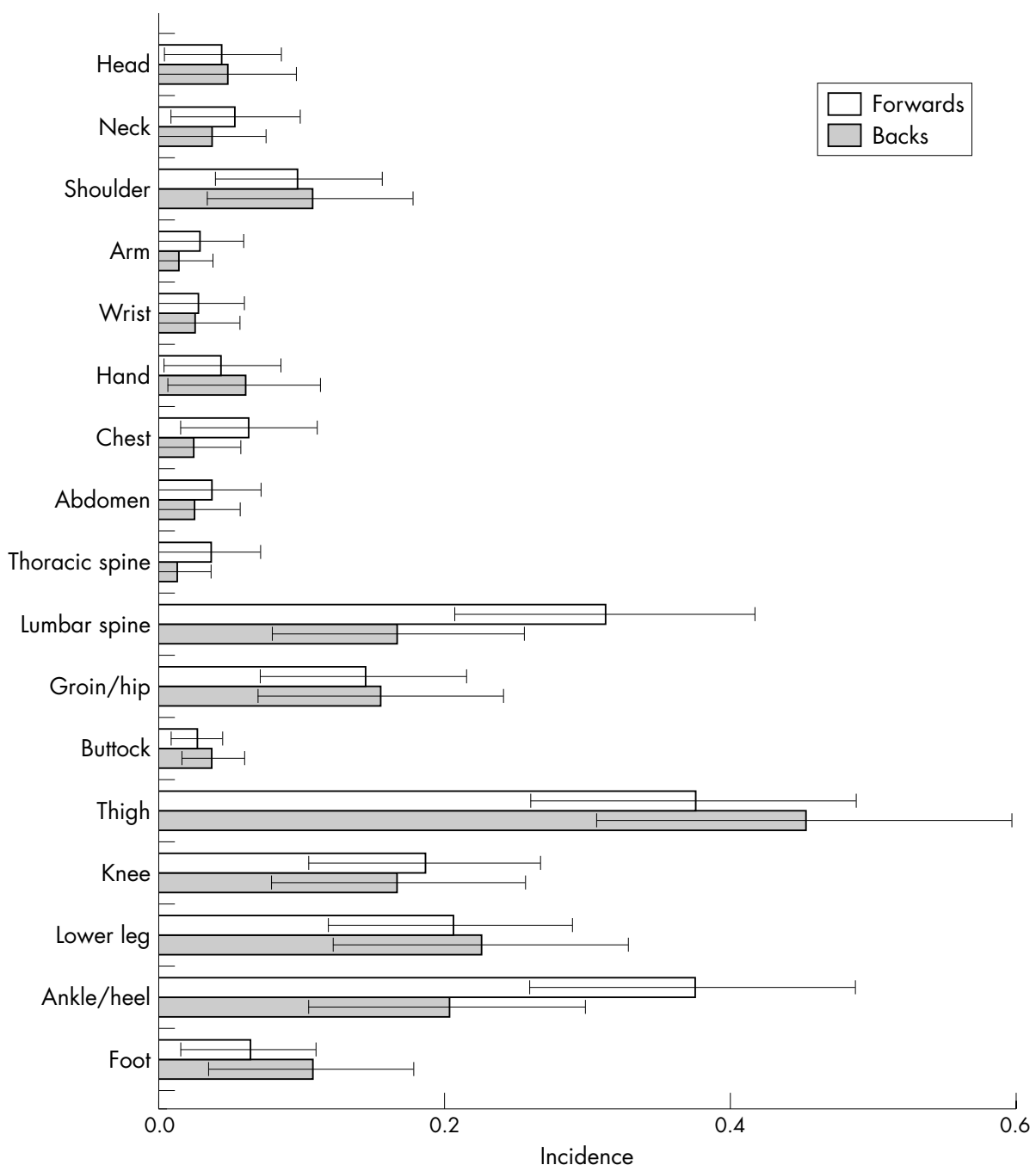

Figure 2 Injury incidence (number per 1000 player-hours) with confidence intervals by anatomical location. 


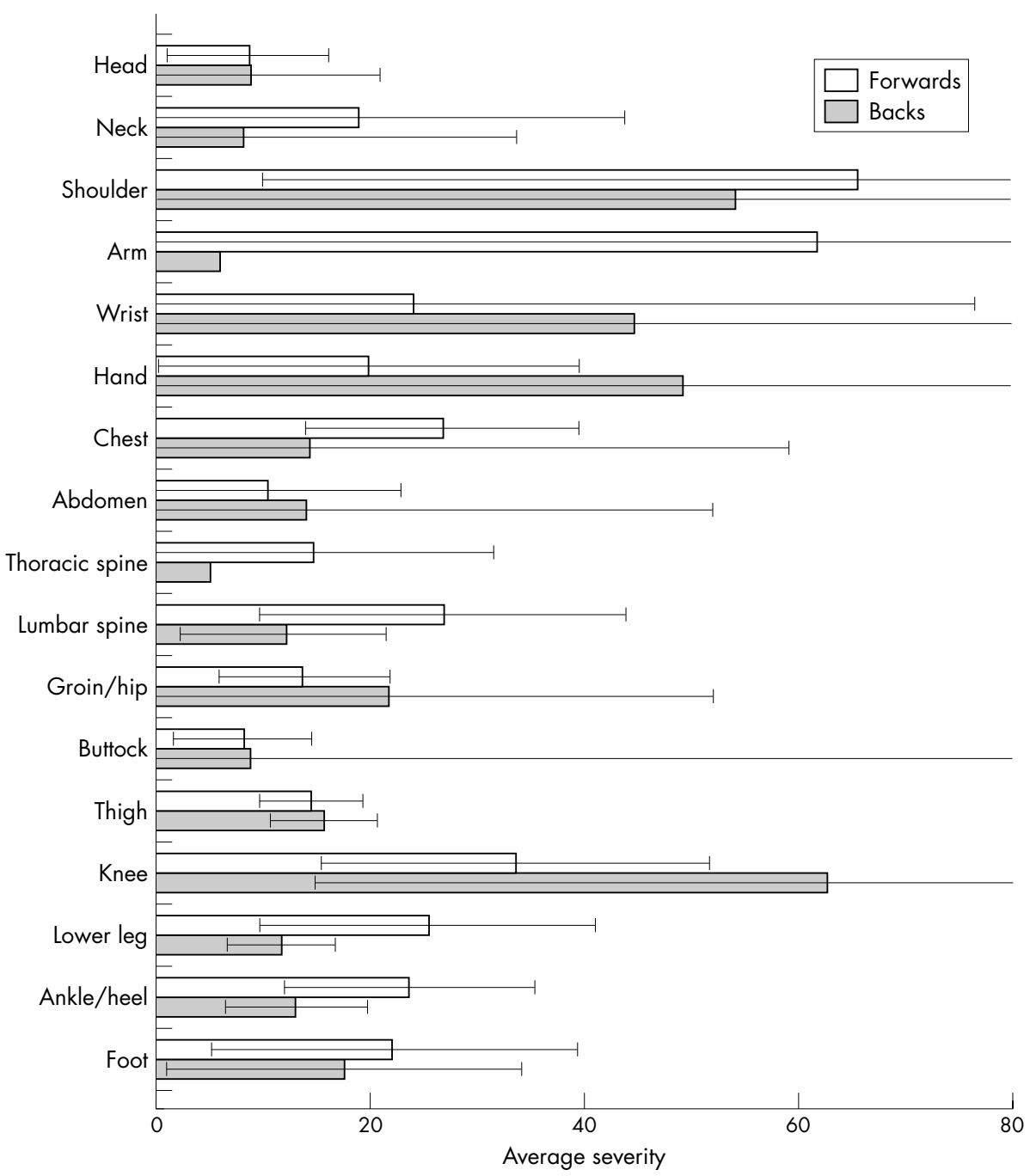

Figure 3 Injury severity (average days absence) with confidence intervals by anatomical location.

backs, 1.1 ( $95 \%$ CI 0.8 to 1.3$)$ ) with a severity of 35 days ( $95 \%$ CI 30 to 41 ) (forwards, 36 (95\% CI 29 to 44); backs, 34 (95\% CI 24 to 45$)$ ).

\section{Nature of injury}

Table 3 provides an overview of the distribution and severity of injuries in terms of their location and pathology. Lower limb injuries made up the greatest proportion of injuries $(68 \%)$, although the severity of upper limb injuries was significantly greater than injuries to all other areas of the body. The two most common pathologies were muscle and tendon injuries and joint (non-bone) and ligament injuries, but joint (non-bone) and ligament injuries were significantly more severe.

Figures 2 and 3 provide overviews of the incidence and severity of injuries as a function of anatomical location for forwards and backs. For the lower extremities, injuries to the thigh were the most common, but injuries to the knee were the most severe. For the upper extremities, injuries to the shoulder were the most common and the most severe.

Table 4 presents the incidences and severities of specific injury diagnoses as functions of injury location and playing position and highlights the five most common injuries for forwards and backs. The incidence of lumbar disc/nerve root injuries was significantly higher for forwards than backs, and most $(55 \%)$ of these injuries was sustained during weight training. Table 5 lists the injuries presenting the greatest risk (total days absence) for forwards and backs.

\section{Time of injury during the season}

Figures 4 and 5 show the incidence and severity of injuries during the season. The incidence of injury was significantly higher during the preseason period (July and August, 2.5 injuries/1000 player-training-hours; $95 \%$ CI 2.0 to 2.9) compared with the first (September to December, 1.4 injuries/1000 player-training-hours; $95 \%$ CI 1.1 to 1.6) and second (January to May, 1.0 injuries/1000 player-traininghours; $95 \%$ CI 0.8 to 1.2 ) parts of the league season. Twenty two per cent of all training occurred during the preseason period, but $34 \%$ of all injuries were sustained at this time. There was a tendency for the severity of injuries to increase in the later part of the season but the differences were not significant.

\section{Injury mechanism}

Figure 6 identifies the main injury mechanisms for forwards and backs. Although most (57\%) training injuries occurred during non-contact training activities, injuries sustained during contact activities were more severe (30 days, 95\% CI 22 to 38) than injuries sustained during non-contact activities ( 19 days, $95 \%$ CI 15 to 23 ). 
Table 4 Incidence (number per 1000 player-hours) and severity (days absence) of specific injuries as a function of playing position

\begin{tabular}{|c|c|c|c|c|c|c|}
\hline \multirow[b]{2}{*}{ Injury (region and diagnostic category) } & \multicolumn{2}{|l|}{ Forwards } & \multicolumn{2}{|l|}{ Backs } & \multicolumn{2}{|l|}{ All } \\
\hline & Incidence & Severity & Incidence & Severity & Incidence & Severity \\
\hline \multicolumn{7}{|l|}{ Head/neck } \\
\hline Concussion & 0.01 & 17 & 0.02 & 13 & 0.02 & 14 \\
\hline Head/facial laceration & 0.02 & 5 & 0.01 & 4 & 0.02 & 4 \\
\hline Cervical nerve root injury & 0.02 & 32 & 0.02 & 11 & 0.02 & 21 \\
\hline \multicolumn{7}{|l|}{ Shoulder } \\
\hline Dislocation/instability, shoulder & 0.03 & 164 & 0.02 & 148 & 0.03 & 157 \\
\hline Acromioclavicular joint injury & 0.07 & 26 & 0.06 & 20 & 0.07 & 24 \\
\hline Rotator cuff/shoulder impingement & 0.01 & 37 & 0.01 & 61 & 0.01 & 49 \\
\hline \multicolumn{7}{|l|}{ Arm/elbow/wrist/hand } \\
\hline Arm fracture & 0.01 & 46 & - & - & 0.01 & 46 \\
\hline Wrist/hand fracture & 0.03 & 25 & 0.02 & 38 & 0.03 & 30 \\
\hline \multicolumn{7}{|l|}{ Chest } \\
\hline Costochondral/sternal injury & 0.04 & 25 & - & - & 0.02 & 25 \\
\hline \multicolumn{7}{|l|}{ Thoracic/lumbar spine } \\
\hline Thoracic facet joint injury & 0.03 & 10 & _- & _- & 0.02 & 10 \\
\hline Lumbar facet joint injury & 0.05 & 7 & 0.02 & 23 & 0.04 & 11 \\
\hline Lumbar disc, nerve root injury & $0.19^{(2=)}$ & 40 & 0.05 & 21 & $0.13^{(5)}$ & 37 \\
\hline Lumbar soft tissue injury & 0.04 & 9 & 0.06 & 6 & 0.05 & 8 \\
\hline \multicolumn{7}{|l|}{ Groin/hip/buttock } \\
\hline Adductor muscle injury* & 0.07 & 16 & $0.10^{(4=)}$ & 31 & 0.08 & 23 \\
\hline Inguinal canal injury & 0.01 & 61 & 0.02 & 7 & 0.02 & 25 \\
\hline \multicolumn{7}{|l|}{ Thigh } \\
\hline Hip flexor/quadriceps muscle injury* & $0.15^{(5)}$ & 9 & $0.17^{(3)}$ & 8 & $0.16^{(3)}$ & 9 \\
\hline Haematoma, thigh & 0.01 & 5 & 0.02 & 5 & 0.02 & 5 \\
\hline Hamstring muscle injury* & $0.28^{(1)}$ & 15 & $0.32^{(1)}$ & 19 & $0.30^{(1)}$ & 17 \\
\hline \multicolumn{7}{|l|}{ Knee } \\
\hline$M C L$ injury & 0.05 & 48 & 0.04 & 24 & 0.05 & 40 \\
\hline $\mathrm{ACL}$ injury & - & - & 0.02 & 245 & 0.01 & 245 \\
\hline $\mathrm{PCL} / \mathrm{LCL}$ injury & 0.01 & 90 & - & - & 0.01 & 90 \\
\hline Knee meniscal/articular cartilage injury & 0.04 & 59 & 0.04 & 65 & 0.04 & 61 \\
\hline Knee joint sprain & 0.02 & 16 & 0.04 & 11 & 0.03 & 13 \\
\hline \multicolumn{7}{|l|}{ Lower leg } \\
\hline Haematoma, calf/shin & 0.02 & 2 & 0.04 & 18 & 0.03 & 11 \\
\hline Calf muscle injury* & $0.17^{(4)}$ & 17 & $0.18^{(2)}$ & 9 & $0.17^{(2)}$ & 14 \\
\hline Tibia/fibula fracture & 0.02 & 132 & 0.01 & 32 & 0.02 & 98 \\
\hline Achilles tendon injury & 0.05 & 67 & 0.06 & 15 & 0.06 & 43 \\
\hline Inferior tibia-fibula syndesmosis injury & 0.04 & 17 & 0.01 & 25 & 0.03 & 19 \\
\hline \multicolumn{7}{|l|}{ Ankle/heel/foot } \\
\hline Ankle joint capsule sprain & 0.03 & 8 & & 9 & & 8 \\
\hline Lateral ankle ligament injury & $0.19^{(2=)}$ & 16 & $0.10^{(4=)}$ & 9 & $0.15^{(4)}$ & 14 \\
\hline Foot stress fracture & 0.02 & 31 & 0.04 & 26 & 0.03 & 28 \\
\hline Haematoma, foot/ankle & 0.01 & 12 & 0.04 & 6 & 0.02 & 8 \\
\hline
\end{tabular}

\section{Training activity}

Table 6 shows the number and average duration of training sessions undertaken by forwards and backs, and table 7 shows the structures of the training programmes of the forwards and backs. The overall incidence (2.1/1000 playertraining-hours; $95 \%$ CI 1.8 to 2.4 ) and severity (27 days; $95 \%$ CI 21 to 32) of injuries sustained during skills training were significantly greater than those sustained during conditioning training (1.6/1000 player-training-hours (95\% CI 1.3 to $1.8) ; 16$ days ( $95 \%$ CI 12 to 20$)$ ). Table 8 shows the incidence and severity of injuries as functions of training activity and playing position. The incidence of injuries sustained during endurance training was higher during running activities (forwards, 3.4 injuries/1000 player-training hours (95\% CI 1.8 to 5.0$)$; backs, 3.5 (95\% CI 1.7 to 5.2$)$ ) than during off-feet endurance activities (forwards, 0.9 (95\% CI 0 to 2.7 ); backs, 2.0 (95\% CI 0 to 5.8$)$ ). Table 9 shows those injuries with the highest incidence and those causing the greatest number of days absence as functions of training activity.

\section{DISCUSSION}

The overall incidence of training injuries using the primary, fully inclusive loss of time definition for injury was $2.0 / 1000$ player-training-hours. This was much lower than the value reported for international players ${ }^{4}(6.1)$ but higher than the value reported for senior amateur players ${ }^{11}(1.3)$. This result is therefore consistent with the hypothesis that the incidence of training injuries reflects playing standard. ${ }^{12-14}$ The incidence was also lower than values reported for professional soccer $\left(3.4,{ }^{9} 5.2^{15}\right)$; this may reflect the greater emphasis placed on weight training in rugby union training programmes compared with soccer. When the secondary, semi-inclusive loss of time definition for injury is considered, the incidence of injury observed in this study (1.2) was similar to that reported for amateur rugby union ${ }^{16}$ (1.3) and semiprofessional $^{6}$ (1.3) and professional ${ }^{5}$ (1.4) rugby league.

The proportion of recurrent training injuries (19\%) was similar to that reported for match injuries ${ }^{1}(18 \%)$. Recurrent training injuries were more severe than new injuries for forwards and backs, and this again highlights the importance of complete and effective rehabilitation. Overall, training injuries were significantly more severe (24 days) than injuries sustained during competition ${ }^{1}$ ( 18 days).

The most common injury mechanism for forwards and backs was running, which accounts for the high proportion of lower limb injuries and the number of hamstring muscle 
Table 5 Injury diagnoses causing the greatest number of days absence for forwards and backs

\begin{tabular}{lll}
\hline Injury & $\begin{array}{l}\text { Total days } \\
\text { absence }\end{array}$ & $\begin{array}{l}\text { Days absence/ } \\
1000 \text { hours }\end{array}$ \\
\hline $\begin{array}{ll}\text { Forwards } \\
\text { Lumbar disc/nerve root injury }\end{array}$ & 840 & 7.5 \\
Dislocation/instability, shoulder & 491 & 4.4 \\
Hamstring muscle injury & 478 & 4.3 \\
Achilles tendon injury & 402 & 3.6 \\
Lateral ankle ligament injury & 332 & 3.0 \\
Calf muscle injury* & 322 & 2.9 \\
MCL injury & 286 & 2.5 \\
Tibia/fibula fracture & 263 & 2.3 \\
Knee meniscal/articular cartilage injury & 234 & 2.1 \\
Acromioclavicular joint injury & 207 & 1.8 \\
Backs & & \\
Hamstring muscle injury* & 502 & 6.0 \\
ACL injury & 489 & 5.8 \\
Dislocation/instability, shoulder & 296 & 3.5 \\
Adductor muscle injury & 249 & 3.0 \\
Knee meniscal/articular cartilage injury & 194 & 2.3 \\
Calf muscle injury* & 140 \\
Hip flexor/quadriceps muscle injury* & 114 & 1.7 \\
Acromioclavicular joint injury & 101 & 1.4 \\
Lumbar disc/nerve root injury & 82 & 1.2 \\
Stress fracture, foot & 79 & 0.9 \\
\hline *Excluding haematomas/contusions. & & \\
ACL, Anterior cruciate ligament; MCL, medial collateral ligament. & & \\
& &
\end{tabular}

injuries, in particular. The incidence, severity, and nature of training injuries were similar for forwards and backs, which suggests that the demands placed on forwards and backs during training were similar. This contrasted with the results reported previously for match injuries, ${ }^{1}$ where, although the incidences and severities of injuries were similar, the injury profiles were significantly different for forwards and backs.
Table 6 Preseason and in-season training exposures for forwards and backs

\begin{tabular}{|c|c|c|c|c|}
\hline & \multicolumn{2}{|c|}{ Forwards } & \multicolumn{2}{|l|}{ Backs } \\
\hline & Number & $\begin{array}{l}\text { Length } \\
\text { (min) }\end{array}$ & Number & $\begin{array}{l}\text { Length } \\
\text { (min) }\end{array}$ \\
\hline $\begin{array}{l}\text { Preseason } \\
\text { In-season }\end{array}$ & $\begin{array}{l}8(3.3) \\
6(2.3)\end{array}$ & $\begin{array}{l}70(24) \\
65(23)\end{array}$ & $\begin{array}{l}8(3.3) \\
6(2.3)\end{array}$ & $\begin{array}{l}65(21) \\
60(20)\end{array}$ \\
\hline
\end{tabular}

Values are number of sessions a week and their length expressed as mean (SD).

A significantly higher incidence of injury was observed during the preseason training period compared with the remainder of the season. In soccer, no difference was observed between the preseason and in-season incidences of injury for professional players, but a higher incidence was observed for youth players. ${ }^{9}$ Low fitness levels ${ }^{17}$ and poor coordination, low oxygen uptake, lack of strength, and poor training progression ${ }^{8}$ have been suggested as factors that may explain these differences. Players who are predisposed to injury because of musculoskeletal or physiological weaknesses may also be more susceptible to injury at the beginning of a season if these weaknesses are not specifically identified and addressed within training programmes.

There were more training sessions on average per week in the preseason than there were in the remainder of the season, and the overall number of hours spent training a week during the preseason (forwards, 560 minutes; backs, 520 minutes) was greater than that during the remainder of the season (forwards, 408; backs, 372). This was similar to that observed in a study of international players preparing for the 2003 Rugby World $\mathrm{Cup}^{4}$ if preseason training is compared with pre-tournament training programme (forwards, $537 \mathrm{~min}$ -
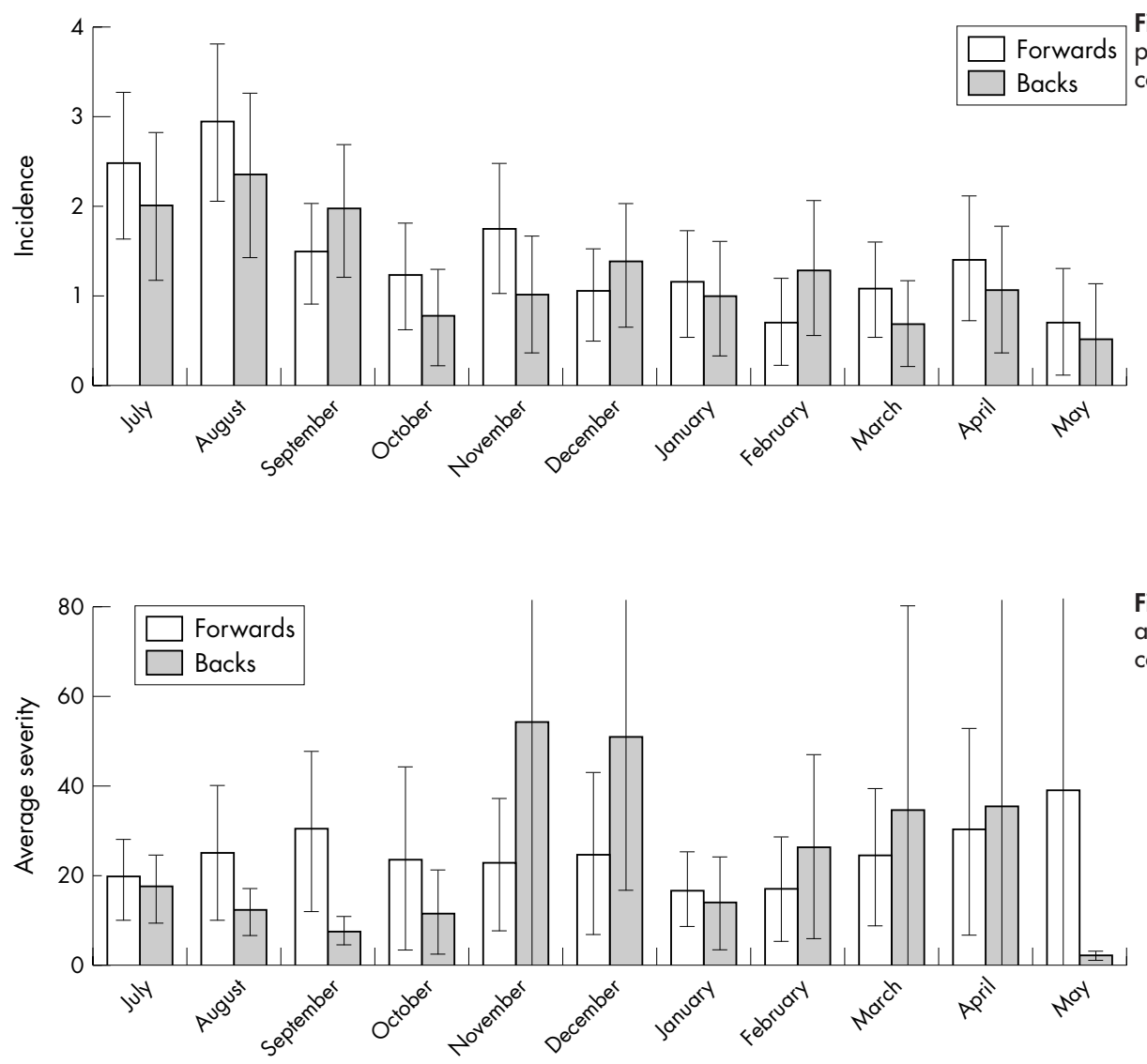

Figure 4 Incidence (number per 1000 player-hours) of training injuries with confidence intervals during the season.

Figure 5 Severity (average days absence) of training injuries with confidence intervals during the season. 


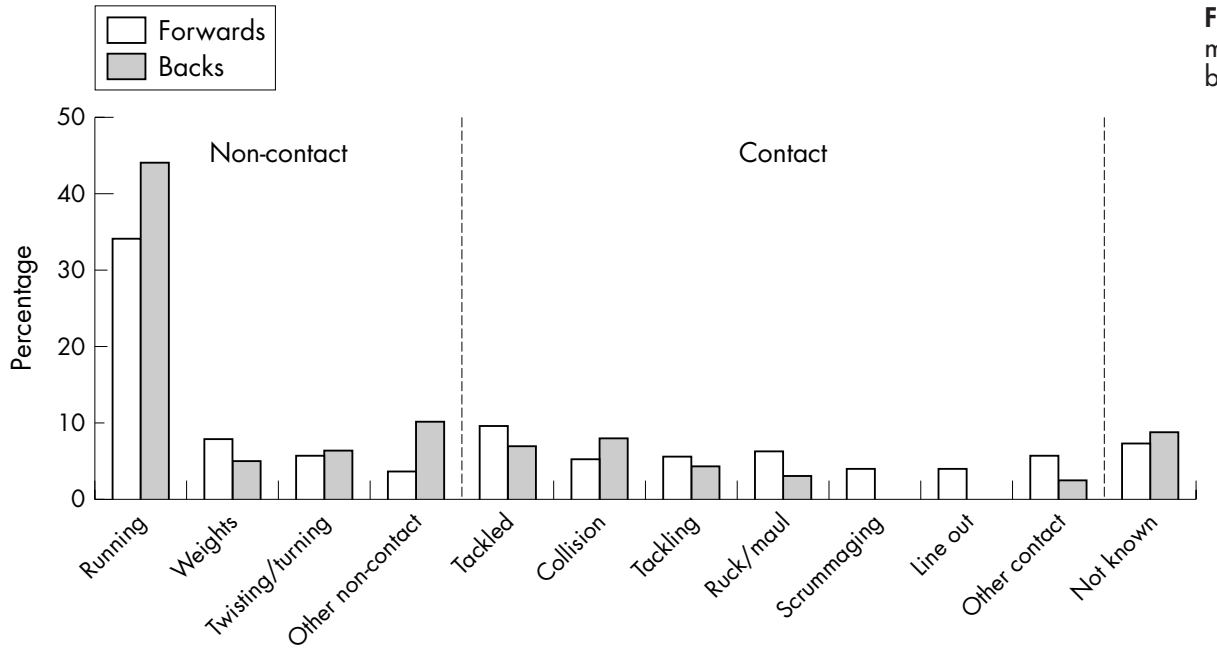

Figure 6 Proportion of injuries by main mechanism for forwards and backs.

Injury mechanism

Table 7 Structures of training programmes for forwards and backs

\begin{tabular}{llllll}
\hline & \multicolumn{2}{l}{ Preseason } & & & \multicolumn{2}{l}{ In-season } \\
\cline { 2 - 2 } \cline { 5 - 6 } & Forwards & Backs & & Forwards & Backs \\
\hline Skills & $238(42)$ & $205(39)$ & & $267(65)$ & $228(61)$ \\
General play/phase work & $72(13)$ & $73(14)$ & & $101(25)$ & $103(28)$ \\
Defence & $35(6)$ & $34(6)$ & & $44(11)$ & $45(12)$ \\
Line outs & $28(5)$ & - & $39(9)$ & - \\
Scrummaging & $17(3)$ & - & $21(5)$ & - \\
Rucking/mauling & $18(3)$ & $13(2)$ & & $14(3)$ & $7(2)$ \\
Other skills & $69(12)$ & $84(16)$ & & $49(12)$ & $72(19)$ \\
Conditioning & $328(58)$ & $326(61)$ & & $143(35)$ & $148(39)$ \\
Weights & $163(29)$ & $161(30)$ & & $92(22)$ & $90(24)$ \\
Speed and agility & $53(9)$ & $60(11)$ & & $22(5)$ & $29(8)$ \\
Endurance & $81(14)$ & $73(14)$ & & $24(6)$ & $21(6)$ \\
Fitness testing & $<5(<1)$ & $<5(<1)$ & & $<5(<1)$ & $<5(<1)$ \\
Other conditioning & $31(6)$ & $33(6)$ & $6(1)$ & $7(2)$ \\
Total training & $566(100)$ & $532(100)$ & & $409(100)$ & $376(100)$ \\
\hline
\end{tabular}

Values are mean training time per week per player in minutes with the percentage of all training in parentheses.

Table 8 Incidence and severity of injuries sustained during various training activities for forwards and backs

\begin{tabular}{|c|c|c|c|c|c|c|}
\hline \multirow[b]{2}{*}{ Training activity } & \multicolumn{3}{|l|}{ Forwards } & \multicolumn{3}{|l|}{ Backs } \\
\hline & $\begin{array}{l}\text { Incidence } \\
(95 \% \mathrm{CI})\end{array}$ & $\begin{array}{l}\text { Severity } \\
(95 \% \text { CI) }\end{array}$ & $\begin{array}{l}\text { Risk } \\
(95 \% \mathrm{Cl})\end{array}$ & $\begin{array}{l}\text { Incidence } \\
(95 \% \mathrm{CI})\end{array}$ & $\begin{array}{l}\text { Severity } \\
(95 \% \text { CI) }\end{array}$ & $\begin{array}{l}\text { Risk } \\
(95 \% \mathrm{Cl})\end{array}$ \\
\hline \multicolumn{7}{|l|}{ Skills } \\
\hline General play/phase work & $2.5(1.9$ to 3.1$)$ & 25 (16 to 34$)$ & $63(60$ to 66$)$ & $2.2(1.6$ to 2.9$)$ & $22(13$ to 30$)$ & 49 (46 to 52$)$ \\
\hline Defence & 2.5 (1.6 to 3.5$)$ & $40(15$ to 65$)$ & 102 (96 to 107) & $2.2(1.2$ to 3.2$)$ & 34 (3 to 65 ) & 75 (69 to 81$)$ \\
\hline Line outs & $1.3(0.6$ to 2.1$)$ & 27 (2 to 52$)$ & $36(32$ to 40$)$ & - & - & - \\
\hline Scrummaging & $1.7(0.6$ to 2.8$)$ & $27(6$ to 49$)$ & 47 (41 to 52$)$ & - & - & - \\
\hline Rucking/mauling & $5.9(3.4$ to 8.5$)$ & 23 (12 to 35$)$ & $138(126$ to 150$)$ & $1.8(0$ to 3.8$)$ & 24 (0 to 82$)$ & $43(33$ to 53$)$ \\
\hline Other skills & $1.1(0.6$ to 1.7$)$ & 15 (6 to 23$)$ & $17(15$ to 19$)$ & $1.6(0.9$ to 2.2$)$ & $23(5$ to 41$)$ & 37 (33 to 40 ) \\
\hline $\begin{array}{l}\text { All skills } \\
\text { nats }\end{array}$ & $2.2(1.8$ to 2.5$)$ & 28 (20 to 34$)$ & 61 (59 to 62) & $2.0(1.6$ to 2.4$)$ & 25 (17 to 34$)$ & 50 (48 to 52 ) \\
\hline \multicolumn{7}{|l|}{ Conditioning } \\
\hline Weights & $0.9(0.5$ to 1.3$)$ & $16(7$ to 26$)$ & 15 (13 to 16$)$ & $0.4(0.1$ to 0.7$)$ & 20 (1 to 38$)$ & $8(7$ to 10$)$ \\
\hline Speed and agility & $1.9(0.9$ to 3.0$)$ & $9(5$ to 14$)$ & 18 (15 to 22$)$ & 2.0 (1.0 to 3.1$)$ & 11 (5 to 18$)$ & 23 (19 to 27$)$ \\
\hline Endurance & $3.0(1.8$ to 4.1$)$ & $13(5$ to 22$)$ & 40 (35 to 44$)$ & $3.1(1.7$ to 4.5$)$ & 15 (8 to 21$)$ & 45 (40 to 50$)$ \\
\hline Fitness testing & $9.8(1.2$ to 18$)$ & $47(0$ to 150$)$ & 457 (398 to 515$)$ & $4.6(0$ to 11$)$ & $8(0$ to 77$)$ & 35 (17 to 52$)$ \\
\hline Other conditioning & $4.5(1.6$ to 7.4$)$ & $22(4$ to 39$)$ & $97(83$ to 111$)$ & $1.5(0$ to 3.1$)$ & $10(0$ to 26$)$ & $14(9$ to 19$)$ \\
\hline All conditioning & $1.7(1.1$ to 2.3$)$ & $17(10$ to 23$)$ & 30 (28 to 32 ) & $1.4(1.0$ to 1.8$)$ & $13(10$ to 17$)$ & $18(17$ to 19$)$ \\
\hline
\end{tabular}


Table 9 Incidence and severity of injuries sustained during various training activities for forwards and backs

\begin{tabular}{|c|c|c|c|c|}
\hline \multirow[b]{2}{*}{ Activity } & \multicolumn{2}{|l|}{ Forwards } & \multicolumn{2}{|l|}{ Backs } \\
\hline & Highest incidence & Most days absence & Highest incidence & Most days absence \\
\hline General play/phase work & Lateral ankle ligament injury & Lumbar disc/nerve root injury & Hamstring muscle injury* & $\begin{array}{l}\text { Knee meniscal/articular } \\
\text { cartilage injury }\end{array}$ \\
\hline Defence & $\begin{array}{l}\text { MCL and acromioclavicular } \\
\text { joint injuries }\end{array}$ & $\begin{array}{l}\text { Dislocation/instability, } \\
\text { shoulder }\end{array}$ & Acromioclavicular joint injury & $\mathrm{ACL}$ injury \\
\hline Line outs & Lateral ankle ligament injury & Achilles tendon injury & - & - \\
\hline Scrummaging & Calf muscle injury* & Calf muscle injury* & - & - \\
\hline Rucking/mauling & Acromioclavicular joint injury & Tibia/fibula fracture & $M C L$ injury & $M C L$ injury \\
\hline Weights & Lumbar disc/nerve root injury & Lumbar disc/nerve root injury & Lumbar disc/nerve root injury & Lumbar disc/nerve root injury \\
\hline Speed and agility & $\begin{array}{l}\text { Lateral ankle ligament and } \\
\text { hamstring muscle* injuries }\end{array}$ & Hamstring muscle injury* & Hamstring muscle injury* & Adductor muscle injury* \\
\hline Endurance & $\begin{array}{l}\text { Hip flexor/quadriceps muscle } \\
\text { injury* }\end{array}$ & Lumbar disc/nerve root injury & $\begin{array}{l}\text { Hip flexor/quadriceps muscle } \\
\text { injury* }\end{array}$ & Hamstring muscle injury* \\
\hline Fitness testing & Several & Achilles tendon injury & Several & Hamstring muscle injury* \\
\hline
\end{tabular}

\section{What is already known on this topic}

A detailed assessment of the incidence and nature of training injuries in rugby union has not been reported previously

utes; backs, 518 minutes) and in-season training is compared with the in-tournament training programme (forwards, 351; backs, 342). A greater emphasis was placed on conditioning training (forwards, 58\%; backs, 61\%) during the preseason, whereas in-season the emphasis moved to skills training (forwards, 65\%; backs, 61\%). However, this change in emphasis resulted mainly from a reduction in the actual time spent on conditioning training rather than from an increase in the time spent on skills training. Within the conditioning element of the training programme, the change from the preseason to the in-season training programme also resulted in an increase in the proportion of lower risk weight training activities (50\% to $63 \%$ ) and a decrease in the proportion of higher risk endurance activities (24\% to $15 \%$ ). These changes contributed to the lower overall incidence of training injuries observed in-season compared with preseason. In a study of international rugby union players, an increase in training volume coincided with an increase in the incidence and severity of training injuries, ${ }^{4}$ a trend that has also been noted in soccer ${ }^{18}$ and rugby league. ${ }^{19}$

Although a high volume of weight training may reduce the overall risk of injury in a training programme, it may increase the incidence of specific injuries. For example, in the present study, forwards sustained a high incidence of lumbar disc/ nerve root injuries during weight training. This may have resulted from suboptimal preconditioning of the muscles that stabilise the lumbar spine or from a progressive overload of the lumbar spine during weight training, possibly exacerbated by poor technique and other lumbar loading activities such as scrummaging. One of the aims of weight training programmes is to develop muscle strength and endurance, which can help to reduce the overall incidence of injury. ${ }^{20}$ Therefore it is essential to take a holistic view of the costs and benefits of weight training. A previous study of international players ${ }^{4}$ highlighted the significant benefits that were gained, in terms of the reduced incidence of injury, from using offfeet endurance training activities such as rowing and cycling rather than running. This benefit was also observed in the present larger study.

The incidence figures derived for specific training activities can be used by fitness advisors for planning and optimising training programmes in order to balance the risks of injury

\section{What this study adds}

- The study provides a detailed analysis of the incidence and severity of training injuries as a function of playing position together with identification of the injuries that cause the greatest loss of time

- The incidence and severity of injuries are also presented as a function of training activity for forwards and backs

against potential improvements in performance. For example, the results presented in table 8 show that those training activities that closely mimic the demands of the game by involving contact and collision elements, such as rucking/ mauling, have the highest risk of injury ( 138 days lost per 1000 training-hours) for forwards. Therefore, if a squad of 15 forwards incorporated two hours of rucking/mauling (5.9 injuries/1000 player-rucking/mauling training-hours) into their weekly training programme (30 player-hours of training), the club could expect, on average, to sustain an injury every six weeks that would result in one forward being unavailable to play for 23 days.

The loss of players as a consequence of training injuries is weighted towards the beginning of the season, as one third of all training injuries were recorded during the preseason. However, based on the average values of incidence and severity of training injuries, a club could anticipate that 1.8 players would be unavailable to play each week because of training injuries, which is equivalent to $5 \%$ of an average club's squad. In addition, as $18 \%$ of a club's players will also be unavailable to play as a consequence of match injuries, ${ }^{1}$ the total impact of injury is that $23 \%$ of an average club's squad will be unavailable for selection at any one time.

\section{ACKNOWLEDGEMENTS}

We acknowledge the work of and thank the doctors, physiotherapists, and fitness and strength and conditioning staff from the following clubs and teams who have recorded injury and training information throughout the project: Bath Rugby (C Mallac, M Yates); Gloucester RFC (N Allen, E Archer, W Diesel, K Owen); England (B Kenny, C Morriss, M Snelling, T Weighmann); Leeds Tykes ( $M$ Blenkinsop, S Carter, I Horsley, M Jones, M Luffman); Leicester Tigers (R Aitkin, C Brookes, R Cross, J Duggan, M Geeson, J Wood); London Irish (A Leaver, R Mack, D Williams); London Wasps ( $\mathrm{R}$ Knibbs, C White); NEC Harlequins (D Bell, P Pook, S Scott, C Steele); Northampton Saints (C Eaton, T Exeter, D Lewindon, J Moore, P Pask); Rotherham Titans (C Bynie, S Raines); Sale Sharks (M Hulme, 
N Johnson, A Perelini, M Sinclair); Saracens ( $\mathrm{P}$ Atkinson, L Dunthorne, P Fox, R Naish, N Roe). We also thank Dr Richard Hawkins (The Football Association Medical and Exercise Science Centre) for his advice, and the Rugby Football Union for their financial support.

\author{
Authors' affiliations \\ J H M Brooks, S P T Kemp, D B Reddin, Rugby Football Union, \\ Twickenham, Middlesex, UK \\ C W Fuller, University of Leicester, Leicester, UK \\ Competing interests: none declared

\section{REFERENCES} \\ 1 Brooks JHM, Fuller CW, Kemp SPT, et al. Epidemiology of injuries in English \\ professional rugby union: part 1 match injuries. $\mathrm{Br} J$ Sports Med \\ 2005;39:757-66 \\ 2 Targett SGR. Injuries in professional rugby union. Clin J Sport Med \\ 1998:8:280-5. \\ 3 Bathgate A, Best JP, Craig G, et al. A prospective study of injuries to elite \\ Australian rugby union players. Br J Sports Med 2002;36:265-9. \\ 4 Brooks JHM, Fuller CW, Kemp SPT, et al. A prospective study of injuries and \\ training amongst the England 2003 Rugby World Cup squad. Br J Sports Med \\ 2005;39:288-93. \\ 5 Phillips LH, Standen PJ, Batt ME. The effects of seasonal change in rugby \\ league on the incidence of injury. Br J Sports Med 1998;32:144-8. \\ 6 Gabbett TJ. Incidence of injury in semi-professional rugby league players. \\ Br J Sports Med 2003;37:36-44.
}

7 Gabbett TJ. Influence of training and match intensity on injuries in rugby league. J Sports Sci 2004;22:409-17.

8 Woods C, Hawkins RD, Hulse MA, et al. The Football Association Medical Research Programme: an audit of injuries in professional football: analysis of preseason injuries. Br J Sports Med 2002;36:436-41.

9 Hawkins RD, Fuller CW. A prospective epidemiological study of injuries in four English professional football clubs. Br J Sports Med 1999;33:196-203.

10 Orchard J. Orchard Sports Injury Classification System (OSICS). Sport Health 1995;11:39-41.

11 Hughes DC, Fricker PA. A prospective survey of injuries to first-grade rugby union players. Clin J Sport Med 1994;4:249-56.

12 Roux CE, Goedeke R, Visser GR, et al. The epidemiology of schoolboy rugby injuries. S Afr Med J 1987;71:307-13.

13 Garraway WM, Lee AJ, Hutton SJ, et al. Impact of professionalism on injuries in rugby union. Br J Sports Med 2000;34:348-51.

14 Quarrie KL, Alsop JC, Waller AE, et al. The New Zealand rugby injury and performance project. VI. A prospective cohort study of risk factors for injury in rugby union football. Br J Sports Med 2001;35:157-66.

15 Hägglund $M$, Waldén M, Ekstrand J. Exposure and injury risk in Swedish elite football: a comparison between seasons 1982 and 2001. Scand J Med Sci Sports 2003;13:364-70.

16 Clark DR, Roux C, Noakes TD. A prospective study of the incidence and nature of injuries to adult rugby players. S Afr Med J 1990;77:559-62.

17 Ekstrand J, Gillquist J. Prevention of sport injuries in football players. Int J Sports Med 1984;5:140-4.

18 Ekstrand J, Waldén $M$, Hägglund $M$. Risk for injury when playing in a national football team. Scand J Med Sci Sports 2004;14:34-8.

19 Gabbett TJ. Incidence of injury in junior and senior rugby league players. Sports Med 2004;34:849-59.

20 Gamble P. Physical preparation for elite-level rugby union football. Strength Conditioning Journal 2004;26:10-23.

\section{ELECTRONIC PAGES}

\section{Online case reports}

$\mathrm{T}$ he following electronic only articles are published in conjunction with this issue of BJSM

Time for tea, anyone?

P McCrory, M Turner, A Johnston

There have been suggestions that urine samples positive for benzoylecognine, the diagnostic metabolite of cocaine, may be the result of consumption Mate de Coca, a commercially available tea made from coca (Erythroxylon coca) leaves.

The Jockey Club in Great Britain commissioned research into this subject as several jockeys have tested positive for benzoylecognine over the past few years. Urine samples collected at various time points within $24 \mathrm{~h}$ after ingestion of a $250 \mathrm{ml}$ infusion of Mate de Coca tea were analysed using three different methods. All samples tested positive for benzoylecognine.

(Br J Sports Med 2005;39:e37) http://bjsm.bmjjournals.com/ cgi/content/full/39/9/e37

\section{Hyponatraemic encephalopathy despite a modest rate of fluid intake during a $109 \mathrm{~km}$ cycle race J P Dugas, T D Noakes \\ Objective: To report a case of exertional hypo- natraemic encephalopathy that occurred despite a}

modest rate of fluid intake during a $109 \mathrm{~km}$ cycling race.

Methods: Men and women cyclists were weighed before and after the race. All subjects were interviewed and their water bottles measured to quantify fluid ingestion. A blood sample was drawn after the race for the measurement of serum $\mathrm{Na}^{+}$concentration.

Results: From the full set of data $(n=196)$, one athlete was found to have hyponatraemic encephalopathy (serum $\left[\mathrm{Na}^{+}\right] 129 \mathrm{mmol} / \mathrm{l}$ ). She was studied subsequently in the laboratory for measurement of sweat $\left[\mathrm{Na}^{+}\right]$and sweat rate.

Conclusions: Despite a modest rate of fluid intake $(735 \mathrm{ml} / \mathrm{h})$ and minimal predicted sweat $\mathrm{Na}^{+}$losses, this female athlete developed hyponatraemic encephalopathy. The rate of fluid intake is well below the rate currently prescribed as optimum. Drinking to thirst and not to a set hourly rate would appear to be the more appropriate behaviour.

(Br J Sports Med 2005;39:e38) http://bjsm.bmjjournals.com/ cgi/content/full/39/9/e38 